\title{
Peranan Pengetahuan Bahasa, Budaya dan Implikasinya terhadap Pembelajaran Public Speaking Mahasiswa Bima
}

\author{
${ }^{1}$ Ariani Rosadi, ${ }^{2}$ Lubis Hermanto \\ ${ }^{1}$ Prodi Ilmu Komunikasi, STISIP Mbojo Bima \\ ${ }^{2}$ Prodi Ilmu Komunikasi, STISIP Mbojo Bima \\ Email : ${ }^{1}$ arianirosadistisipmbojo@gmail.com, ${ }^{2}$ lubis.hermantostisipmbojo@gmai.com
}

\author{
Article Info \\ Article history: \\ Article Accepted: 23 Juni 2021 \\ Publication : 11 July 2021
}

Keywords:

language, culture, Public Seaking

\begin{abstract}
Abstrak
In recent years, the challenges of the disruptive era should be a positive impact on society, especially on young generations. It is necessary to improve language skills and adapt to the wider community, including its culture, especially for Bimanese students, West Nusa Tenggara. Therefore, this study aims to identify the role of language, cultural knowledge, and its implications for public speaking learning of Bimanese students of the communication science study program, Mbojo Bima College of Social and Political Sciences (STISIP) Mbojo Bima. The students involved in this study were in the fourth semester and the research method was ethnographic research. It is a qualitative research approach that allows the researcher to engage as participant-observation. Data were collected through observation, in-depth interviews, and video among ten Bimanese students. The informants originally came from Bima. The results of this research show that: (a) for Bimanese students, language and culture play a vital role in creating and maintaining communication. They use Bahasa Indonesia in formal context in which the audience comes from different cultures. However, some chose to mix Indonesian (official language) and Mbojo language (Local language) for audiences from the same culture, old people and less educated people as the proper way to respect them; (b) language and culture are inseparable parts and influential to the individuals' ways of thinking and also how they describe the world or realities in the coordinate relationship and $(c)$ Bimanese students could identify subordinate relation involved in learning about aspects of linguistics and ethic of language during public speaking learning.

This is an open access article under the Lisensi Creative Commons Atribusi-BerbagiSerupa 4.0 Internasional
\end{abstract}

Corresponding Author:

Ariani Rosadi

Prodi Ilmu Komunikasi, STISIP Mbojo Bima

Email: arianirosadistisipmbojo@gmail.com

\section{PENDAHULUAN}

Dalam dunia pendidikan, umumnya peserta didik telah diajarkan pendidikan bahasa daerah, bahasa Indonesia, dan bahasa Inggris. Kedudukan bahasa-bahasa ini mempunyai hak masing-masing. Kapan, dimana dan konteks seperti apa yang biasa digunakan. Meskipun Bahasa Inggris sebagai bahasa asing masuk sebagai salah satu penilaian studi akademik, namun bahasa ini perlu waktu, tenaga dan pikiran untuk membiasakannya digunakan oleh pelajar daerah bukan penutur aslinya (non-native speaker). Tidak sedikit juga dari pelajar daerah yang kesulitan berinteraksi di ruang publik dengan menggunakan bahasa Indonesia yang sesuai dengan kaedah-kaedah bahasa Indonesia. Hal ini bisa dipengaruhi oleh berbagai macam faktor (Marlina, 2019).

Bahasa daerahpun masih terdengar dalam berbagai pembicaraan baik ketika berdialog maupun monolog di depan khalayak pada konteks formal. Hal ini juga bisa dilihat dari sudut pandang gaya komunikasi yang melekat pada setiap daerah. Gaya komunikasi tidak membagi 
komunikasi konteks-tinggi maupun rendah. Walaupun masih dalam budaya yang sama, tetapi ada gaya komunikasi yang paling mendominasi Mulyana ( dalam Simatupang \& Lubis, 2015). Seperti hasil penelitian terdahulu yang menyebutkan bahwa terdapat kecenderungan menggunakan gaya komunikasi konteks-rendah pada gaya bicara mahasiswa asal batak di Yogyakarta yang lugas, langsung dan eksplisit serta logat mereka yang kental meskipun berada di daerah lain (Simatupang \& Lubis, 2015).

Dibalik gaya komunikasinya mahasiswa batak yang berkonteks-tinggi, mempunyai kekayaan budaya yang mengajarkan kebaikan kepada sesama manusia. Apalagi toleransi antar budayapun tetap menjadi prioritas utama yang selalu ditanamkan di sekolah.

Begitupun yang terjadi di Bima, Nusa Tenggara Barat, budaya "meci angi" yang artinya saling menyayangi tetap dijalankan. Apalagi bila sedang berada di perantauan. Semboyan "maja labo dahu" juga secara garis besarnya yaitu malu dan takut menjadi pengingat bagi masyarakat setempat. Namun, masih ada yang menganggap bahwa wilayah timur seperti Bima dengan stereotype gaya komunikasi masyarakatnya menggunakan intonasi nada bicara lebih tinggi, lugas, lantang, serta eksplisit dibandingkan dengan daerah jawa. Gaya komunikasi ini mirip dengan orang batak. Berbeda dengan orang jawa yang berada di Bima, sebagian besar mereka menggunakan intonasi suara yang lembut.

Terlepas dari hal tersebut, semuanya kembali kepada kepribadian seseorang, karena gaya komunikasi konteks tinggi atau rendah tidak bisa menjadi tolak ukur untuk menentukan watak asli dan prilaku seseorang. Namun, peran bahasa dan budaya tidak bisa dipisahkan dari ruang lingkup komunikasi. Jikapun ada hal yang dirasa aneh atau berbeda dalam komuniksi hal itu bisa saja terjadi karena beberapa alasan atau sering disebut dengan noise.

Gangguan komunikasi (noise) bisa terjadi dalam proses berbicara baik dalam bentuk prasangka-prasangka, lamunan, perasaan yang tidak baik dan pengacau indra (suara yang terlalu keras atau lemah, bau menyengat, udara panas). Terkadang intonasi yang tinggi, dipahami seseorang bahwa orang tersebut sedang marah. Padahal memang pembawaanya seperti itu. Hal ini akan mengejutkan seseorang yang tidak biasa dengan gaya bicara yang lantang. Prasangka seperti ini sering terjadi di beberapa kesempatan (Damayanti \& Purnamasari, 2019).

Seperti kejadian yang pernah peneliti alami ketika sedang ingin membeli bakso di bakso orang jawa, ada seorang ibu dari masyarakat setempat yang memang di daerah tersebut gaya bicaranya dengan intonasi nada tinggi sudah biasa. Ibu itu mengatakan sesuatu dengan berteriak dari depan jalan "Mas...bakso mas bungkus satu saya ditunggu di ojek". Namun, si bapak pemilik warung bakso memilih untuk diam. Akhirnya tidak lama ibu itu mendatangi si bapak pemilik bakso dan untuk kedua kalinya menyampaikan ungkapan yang sama. Namun, si bapak pemilik warung bakso rupanya sudah kesal dengan ibu pembeli bakso yang sempat berteriak tadi. Hal ini jelas terlihat dari raut wajah bapak pemilik bakso tersebut. Bapak tersebut mengatakan "Bu, jangan teriak seperti itu lagi ya... saya tidak suka!” dengan wajah yang sangat kesal. Sementara, sang ibu tadi berusaha tenang dan meminta maaf karena sadar dirinya yang salah.

Dari realitas di atas, terdapat gangguan komunikasi yang terjadi antara pembeli dan pedagang. Secara isi pesan tidak ada masalah, tetapi cara penyampainnya dengan intonasi tinggi, tidak seindah yang dirasakan oleh bapak pemilik bakso jawa tadi yang memang budaya aslinya berbeda dari ibu tersebut. Hal semacam ini tidak bisa selamanya dianggap masalah kecil karena dapat menimbulkan konflik. Oleh karena itu, secara umum sangat penting bagi masyarakat dan secara khusus bagi mahasiswa untuk mempelajari ilmu komunikasi terlebih apabila digunakan dalam situasi formal di ruang publik.

Masyarakat, terutama mahasiswa Bima juga membutuhkan pendidikan ilmu komunikasi yang memadai. Mengingat mahasiswa Bima juga mempunyai potensi besar menjadi orangorang penting di daerahnya dan di beberapa kota besar. Mahasiswa Bima yang bersekolah di bima cukup kritis dalam menanggapi kebijakan-kebijakan daerah, isu politik dan masalah sosial lainnya. Tidak jarang aksi mereka muncul di media online daerah sebagai bentuk penyampaian aspirasi dari masyarakat Bima lainnya. 
Untuk itu, adanya mata kuliah bahasa, komunikai budaya lokal, komunikasi antar budaya serta public Speaking di Program Studi Ilmu Komunikasi STISIP Mbojo Bima tidak hanya menambah kolaborasi pengetahuan mereka ketika ingin berbicara di depan publik, tetapi juga pengontrol diri mereka ketika ada oknum yang bermaksud mengadu domba. Dengan belajar dan latihan Public Speaking, mahasiswa dapat mengasah kecakapan menggunakan bahasa Indonesia yang baik dan benar sesuai intonasi, konteks, tujuan, isi pesan, pemilihan kosa kata maupun pengucapannya.

Kolaborasi pembelajaran Public Speaking dengan pengetahuan bahasa dan budaya tentunya akan menambah wawasan yang luas bagi calon sarjana ilmu komunikasi. Apa yang disajikan oleh public speaking saat ini tidak hanya bersifat praktik, tetapi juga bersifat kontekstual (Wulandari, 2017). Namun yang paling utama juga bagi seorang Public Speaker mengolah faktor internal seperti pita suara, lidah, gigi, dan bibir sedangkan faktor non fisik di antaranya adalah kepribadian, karakter, temperamen, bakat, cara berfikir dan tingkat intelegensia. Sedangkan faktor eksternal yaitu tingkat pendidikan, kebiasaan dan lingkungan pergaulan. Hal ini diperlukan untuk meningkatkan keterampilan yang dimiliki (Fitrananda et al., 2018).

Jika hasil penelitian sebelumnya mengidentifikasi gaya komunikasi mahasiswa dari suku batak, maka penelitian ini meninjau lebih luas dari sisi perananan pengetahuan bahasa dan budaya, namun secara khusus diteliti dalam mata kuliah public speaking pada mahasiswa program studi ilmu komunikasi Sekolah Tinggi Ilmu Sosial dan Ilmu Politik Mbojo Bima (STISIP) Mbojo Bima yaitu mahasiswa semester empat tahun akademik 2020-2021. Berdasarkan pengamatan selama mengajar, penampilan awal mahasiswa pada mata kuliah public speaking masih diwarnai dengan logat bahasa daerah yang kental dan penggunaan bahasa Indonesia yang kurang maksimal. Sehingga, peneliti mengangkat judul tersebut.

Adapun rumusan masalah dalam penelitian ini antara lain sebagai berikut?

1) Bagaimana peranan pengetahuan bahasa, budaya dan implikasinya terhadap pembelajaran Public Speaking pada mahasiswa Bima Program Studi Ilmu Komunikasi STISIP Mbojo Bima pada semester empat tahun akademik 2020-2021?

2) Bagaimana pemahaman pola hubungan bahasa dan budaya dan implikasinya terhadap pembelajaran Public Speaking mahasiswa Bima Program Studi Ilmu Komunikasi STISIP Mbojo Bima pada semester empat tahun akademik 2020-2021?

\section{METODE PENELITIAN}

Jenis penelitian yang digunakan dalam penelitian ini adalah kualitatif dengan pendekatan etnografi. Ada tiga dimensi etnografi yang perlu diperhatikan antara lain keterlibatan dan partisipasi dalam topik yang dipelajari, perhatian terhadap konteks sosial pengumpulan data, dan kepekaan terhadap bagaimana subjek peneliti direpresentasikan dalam teks penelitian Marvasti (dalam Windiani \& Nurul, 2016).

Peneliti menggunakan teknik purposive sampling untuk kelompok masyarakat yang dipilih menjadi objek penelitian. Mereka adalah sekelompok orang berusia masih cukup muda dan tengah menempuh pendidikan di Kota Bima, tepatnya di Program Studi Ilmu Komunikasi STISIP Mbojo Bima. Selain sebagai peneliti, peran peneliti di kampus ini juga sebagai staf pengajar di program studi Ilmu Komunikasi ini. Peneliti mempunyai kesempatan untuk memahami gejala empiris (kenyataan) yang ditunjukkan secara sengaja maupun tidak oleh mahasiswa-mahasiwa Bima di Program Studi ini baik itu penggunaan bahasa maupun aspekaspek yang berkaitan dengan budaya yang melekat pada diri mereka.

Mahasiswa-mahasiswa tersebut adalah Mahasiswa yang berada pada semester empat tahun akademik 2020-2021(angkatan 2019) Prodi Ilmu Komunikasi STISIP Mbojo Bima. Terdapat dua kelas pada semester ini, namun peneliti memilih semua kelas pada semester empat ini yaitu kelas A dan B. Angkatan pada semester ini mempunyai perbedaan yang sedikit lebih mencolok dibanding semester-semester sebelumnya yang pernah diajarkan. Secara objektif, 
berdasarkan proses pengamatan yang cukup panjang, kelas 4A dan 4B ini berusaha menampilkan diri mereka di depan layar kamera secara maksimal.

Ditentukannya Public Speaking sebagai mata kuliah yang digunakan adalah untuk mengamati penggunaan bahasa dan budaya mereka karena didalamnya terdapat unsur-unsur kompleks yang dapat menunjukkan pengetahuan (knowledge) bahasa dan budaya serta keterampilan (skill) berbicara mereka. Cara mereka memahami keseluruhannya dapat diidentifikasi melalui mata kuliah ini juga.

Keterlibatan etnografer untuk berpartisipasi sebagai pengamat, baik secara terangterangan atau diam-diam untuk mengamati apa yang terjadi dalam kehidupan masyarakat sehari-hari merupakan ciri khas dari penelitian etnografi Bate ( dalam Achmad \& Ida, 2018). Teknik pengumpulan data pada pendekatan etnografi juga meliputi catatan lapangan, alat perekam gambar, artefak dan benda lain yang mendokumentasikan suasana budaya yang dipelajari (Wijaya, 2018). Etnografi juga mengatur analisa data yang meliputi interpretasi makna dan fungsi berbagai tindakan manusia secara eksplisit dengan penjelasan secara deskripsi dan verbal Denzin ( dalam Iswatiningsih, 1994). Untuk wawancara yang mendalam, peneliti hanya memilih lima dari perwakilan setiap kelas sebagai informan. Namun, pada penelitian ini terdapat satu orang mahasiswa yang budaya aslinya dari Jawa yaitu seorang mahasiswi berinisial ER. Namun, dia tumbuh besar dan bersekolah di Kota Bima bersama kedua orangtuanya.

\section{HASIL DAN PEMBAHASAN}

Pembahasan pada penelitian etnografi ini telah dibatasi pada ruang lingkup unit pada satuan pendidikan yang sudah dijelaskan pada bagian sebelumnya. Berangkat dari paradigma interpretatif atau konstruktivis, peneliti menguraikan pengalamannya selama mengajar dan mempelajari serta memperbaiki hal-hal yang seharusnya dimaksimalkan pada mata kuliah public speaking dengan melibatkan pengetahuan bahasa dan budaya yang telah dipelajari mahasiswa.

Paradigma konstruktivis menjelaskan tentang kegiatan peneliti dalam memahami berbagai macam fenomena dari cara orang-orang berinteraksi dalam kehidupan sehari-hari yang bertujuan untuk menjelaskan suatu budaya yang bisa bersifat material dan non material. Seluruh komponen yang tampak secara fisik yang diciptakan oleh interaksi antar manusia termasuk pada komponen kebudayaan material. Sementara pemikiran, bahasa, nilai- nilai, kepercayaan, perilaku, dan institusi sosial merupakan bentuk dari aspek kebudayaan non material Stolley dalam (Pratama, 2019)

Secara domain, mereka datang dari berbagai macam kecamatan di kota maupun kabupaten Bima. Dengan letak geografis Program Studi Ilmu Komunikasi STISIP Mbojo Bima yang berada di kelurahan Mande, Kecamatan Mpunda, Kota Bima, maka setidaknya para mahasiswa yang jauh dari daerah aslinya di kabupaten Bima tersebut banyak menghabiskan waktu di kota Bima.

Hal tersebut menciptakan ruang baru untuk mereka mengetahui lebih dalam variasi dialek bahasa Bima itu sendiri. Secara konseptual, dialek merupakan subdivisi dari bahasa (Lauder, 2002). Namun, penelitian ini tidak membahas secara detail variasi bahasa bima lebih mendalam karena hal tersebut dapat ditemukan pada penelitian yang berfokus pada dialek bahasa bima.

Berdasarkan hasil wawancara mendalam kepada beberapa mahasiswa perwakilan dari dua kelas tersebut, peneliti mengidentifikasi bahwa mahasiswa Bima cinta Bahasa Indonesia, tetapi juga tidak bisa meninggalkan bahasa daerahnya yaitu bahasa bima dimanapun berada. Bahkan mereka mengakui bahwa peran bahasa Indonesia sangat penting, terutama pada saat bertemu dengan orang baru yang terlihat berbeda budaya. Seperti apa yang disampaikan seorang mahasiswa berinisial LS yang berasal dari Kota Bima ini "penting buk, karena kalau bagi saya bertemu dengan teman baru juga harus pakai Bahasa Indonesia". (Hasil wawancara pada tanggal 2 Juni 2021) . Beberapa mahasiswa juga menjawab hal senada. 
Selanjutnya Peneliti masuk kepertanyaan yang mengarah kepada peranan pengetahuan bahasa dan budaya untuk public speaking. Mahasiswi berinisial FT menjawab " Misalkan, kita berbicara di tempat umum, di desa Kowo khususnya, karena kebanyakan di desa itu mungkin orang tua dahulunya pendidikannya belum tinggi. Otomatis kita juga menggunakan bahasa daerah kita untuk mereka bisa langsung mencerna apa yang dibicarakan oleh orang tersebut." Hal ini menggambarkan bahasa sangat dipengaruhi oleh latar belakang pengetahuan dan pendidikan. Sehingga, penggunaan bahasa daerah pada acara-acara formal perlu menggunakan dua bahasa yaitu Bahasa Indoensia dan bahasa bima.

Hal serupa diungkapkan juga oleh IK, seorang mahasiswa yang berasal dari kecamatan Wera, IK menyatakan bahwa " kalau di tempat saya bu, bahasa daerah itu perlu digunakan ketika berbicara dengan yang lebih tua karena kalau kita menggunakan Bahasa Indonesia saja dibilang kurang sopan apalagi yang memang asli besar di bima tiba-tiba pakai Bahasa Indonesia itu sombong katanya." (Hasil wawancara pada tanggal 2 Juni 2021). Hal ini menandakan bahwa eksistensi penggunaan bahasa daerah sangat berkaitan dengan norma-norma sosial dan kebiasaan orang tua dahulu. Penting halnya untuk mengetahui siapa audiens dan topik apa yang akan disampaikan serta di mana tempat public speaking-nya guna menata pesan dengan bahasa dan gaya bahasa yang bervariasi De Vito dalam (Swestin, 2011)

Senada juga dengan hal di atas, penggunaan bahasa daerah sangat di perlukan untuk mengatasi kesenjangan tingkat pendidikan, sosial dan perbedaan usia. Penggunakan bahasa daerah di tempat formal masih menjadi kebiasaan yang kental, meskipun penggunaanya tidak sebanyak penggunaan Bahasa Indonesia pada kegiatan-kegiatan formal yang khalayaknya di dominasi oleh orang-orang tua dan berasal dari satu budaya yang sama. Tetapi, akan menjadi berbeda ketika audiensnya dari budaya yang berbeda. Maka, bahasa yang mendominasi adalah Bahasa Indonesia. Sebagai bahasa pemersatu, Bahasa Indonesia bisa dipahami oleh berbagai macam kalangan.

Seperti yang diungkapkan oleh ER, dia mengatakan bahwa "Pengetahuan bahasa dan budaya itu penting karena tidak semua orang yang mendengarkan kita berbicara di depan publik, orang yang mendengarkan kita itu dari budaya yang sama bisa jadi aslinya orang jawa tapi, besar di Bima. Jadi menurut saya, penting tahu cara berbicara menggunakan bahasa Indonesia itu termasuk ejaannya, cara pengucapannya dan cara menyusun kata-kata itu biar tidak membosankan."(Hasil wawancara pada tanggal 2 Juni 2021) Dari pernyataan ini, dapat diaartikan bahwa ER memahami apa yang dialami oleh seseorang yang budaya nenek moyangnya berbeda.

Adapun mahasiwa yang berpendapat bahwa penggunaan Bahasa Indonesia yang baik dan benar juga perlu dipelajari dalam mata kuliah public speaking karena berbicara di depan umum bukanlah hal yang mudah. Seperti yang disampaikan oleh PW, "Saya sering menggunakan kata semisalnya dan setelah saya pikir-pikir kenapa ya saya selalu mengulang kata-kata ini dan ibu dosen waktu mengajar public speaking suka menegur saya untuk menggunakan pembendaharaan kata yang lain saja masih ada persamaan kata semisalnya yang sesuai konteks. Saya merasa juga seperti itu, ya mungkin karena saya kurang membaca dan hanya mendengarkan kata semisalnya. Saya sering mendengar kata semisalnya digunakan dalam kegiatan-kegiatan anak muda yang saya ikuti karena saya yakini itu adalah bahasa baku." (Hasil wawancara pada tanggal 2 Juni 2021).

Sebenarnya tidak ada yang salah dari kata "semisalnya", namun pada penggunaannya kata tersebut sering diulang-ulang. Pernyataan PW menyiratkan bahwa pengulangan (repetition) kata "semisalnya" sering digunakan dalam mengungkapkan pendapat. Hal ini menjadi sesuatu yang perlu dikoreksi agar pemilihan kata tidak monoton. Padahal menurut KBBI , kata "semisal" bisa bersinonim seumpama, ibarat, dan seperti. Dalam ilmu public speaking hal ini kurang menarik untuk didengar karena terlalu sering diucapkan.

Dalam penelitian ini, peneliti meninjau bahasa dan budaya Bima umumnya berada pada pola hubungan yang koordinatif dan subordinatif. Dua hubungan ini mempunyai ciri khas masing-masing. Hal ini tergambar melalui fenomena-fenomena yang terjadi selama menjadi 
pengajar mereka serta ikut menjadi bagian dari interaksi sosial mereka. Terlepas daripada dua hubungan ini, peneliti memandang bahwa budaya yang berkaitan dengan pendidikan yaitu budaya literasi membaca harus lebih ditonjolkan agar perbendaharan kata mereka menjadi lebih beragam dan mempelajari budaya bahasa serta cara berpikir daerah lain di dalam maupun luar negeri.

Teori relativitas bahasa yang dikemukaan oleh Sapir-Whorf mengandung pola hubungan koordinatif (Mujib, 2009). Hal ini terlihat dari pernyataan Sapir-Whorf bahwa bahasa, budaya dan cara berpikir masyarakat saling berpautan sebagai contoh penamaan suatu tempat adalah bentuk dari konsep relativitas linguistic yang perumusannya hipotesis Sapir - Worf. Hipotesis Safir - Worf (dalam Camalia, 2015\& Deliani, 2012)

Setiap daerah pasti memiliki ciri khas dari bahasanya masing- masing. Orang Bima biasa menggunakan ungkapan kalembo ade. Menurut penelitian terdahulu terdapat dua implikatur dari ungkapan kalembo ade Pertama, implikatur dari ungkapan kalembo ade berbentuk deklaratif dan imperatif. Kedua, fungsi implikatur dari ungkapan kalembo ade berupa 1) memohon, 2) menasehati, 3) menyuruh, 4) mengharapkan, 5) menyarankan, 6) membujuk, 7) berterima kasih, 8) menyindir, 9) menyembunyikan umpatan, 10) menyatakan penyesalan, dan 11) menyatakan kerendahan hati. Selain fungsi-fungsi tersebut, fungsi utama dari implikatur kalembo ade adalah fungsi kesopanan. Ungkapan ini memiliki makna berbeda-beda (Bulan, 2011\&Wt, 2014) Tetapi, ungkapan ini sangat besar maknanya dan daerah lain belm tentu memiliki ungkapan seperti ini. Satu ungkapan memiliki arti yang luas. Jika ada orang Bima yang menyatakan ini, berarti ada makna dibaliknya. Peneliti menyiratkan hal ini sebagai ungkapan penanda adanya pola hubungan koordinatif antara bahasa dan budaya.

Hasil kajian literature sebelumnya berkaitan dengan hubungan subordinatif yaitu terjadinya perubahan bahasa yang diakibatkan perubahan budaya meliputi: (a) aspek-aspek linguistic, terutama pada morfologi; (b) etika berbahasa yang mengatur bagaimana kapan dan bagaimana bahasa digunakan sesuai dengan norma-norma sosial; (c) bahasa merupakan cerminan dari kebudayaan. Kajian bahasa dan budaya disebut dengan istilah Antropolinguistik (Mujib, 2009).

Hubungan subordinatif antara bahasa dan budaya juga terlihat dari aspek-aspek linguistik yang melekat pada diri individu yang menggunakan bahasa tersebut. Secara konsep bahasa, mahasiswa yang diwawancarai memahami bahwa bahasa adalah alat komunikasi. Penggunaan bahasa daerah digunakan ketika berada di rumah. Sedangkan di kampus, mereka menggunakan dua bahasa yaitu bahasa daerah dan bahasa Indonesia. Namun, Bahasa Indonesia hanya digunakan untuk berkomunikasi dengan dosen dan teman-temannya di forum resmi. Realitasnya di kehidupan sehari-hari mereka cenderung menggunakan bahasa Bima. Hal ini mempengaruhi variasi bahasa mereka ter masuk dalam mengucapkan kosa kata berbahasa Indonesia. Hubungan subordinatif ini telah telah terjadi sejak dahulu.

Dalam bahasa daerah Bima (Mbojo) pengucapan kata yang mendapat imbuhan "m" ini terjadi pada saat mengucapkan kata yang berakhiran huruf vocal fiko yang berarti telinga, masyarakat bima pada umumnya bisa mempersingkat kata "telingamu" menjadi fikom dari kata fikomu. Nasal $/ \mathrm{m} /$ setelah kata fiko ditandai sebagai imbuhan akhiran dari kata $m u$ atau maksudnya milikmu. Secara gramatikal hal ini dapat dipahami. Tetapi tidak berlaku untuk kata dasar yang berakhir konsonan.

Secara gramatikal ada juga kata dasar yang terdengar mempunyai imbuhan yang berbunyi nasal $/ \mathrm{m} /$ dan $/ \mathrm{n} /$. Padahal tidak ada kaitannya secara tata bahasanya. Seperti yang disampaikan oleh WU tentang kebiasaan anak-anak di tempatnya suka mengucapkan kata satu menjadi satun, dua menjadi duan. Seharusnya kata-kata tersebut tanpa bunyi /n/. Namun ada juga orang dewasa yang mengucapkan satum, duam, tigam. (Hasil wawancara pada tanggal 2 Juni 2021) . Berdasarkan hasil rekaman video mereka, masih ada yang mengucapkan adanya kosa kata Bahasa Indonesia yang digunakan oleh masyarakat Bima pada umumnya sejak dulu masih dipengaruhi oleh kebiasaan pengucapan bahasa daerah yang kental. Sehingga hal ini dapat diwarisi oleh keturunannya. Namun, apabila keturunan tersebut belajar lebih baik dan 
menyadari penggunaan EYD ( Ejaan Yang Disempurnakan) Bahasa Indonesia yang baik dan benar itu sangat penting maka hal tersebut dapat diminimalisir bahkan hilang dengan sendirinya.

WU juga menyadari dalam mengucapkan kata "toko", dulu ia masih menyebutnya "tokoh". Jelas hal ini berbeda makna "toko" adalah bangunan yang digunakan sebagai tempat berdagang, sedangkan "tokoh" merupakan individu rekaan yang berada dalam suatu cerita atau orang yang memiliki pengaruh. Hal ini menunjukkan adanya keterkaitan bahasa dan budaya yang terjadi selama ini yaitu pada kata-kata yang mengalami perubahan makna pada kata yang ditambahkan konsonan dibelakangnya baik secara tertulis maupun lisan. Jelas hal ini dapat berhubungan erat dengan literasi.

Budaya literasi juga sangat berpengaruh dalam kecakapan berkomunikasi tidak hanya dari isi utama pesan, tetapi juga dalam bahasa yang digunakan untuk penyampaikan ide atau gagasan. Hal ini terjadi karena kurangnya kesadaran pemahaman dan pengembangan literasi yang intensif. Literasi didefinisikan sebagai suatu simbol, sistem dan tata bunyi yang mengandung makna dan mencakup suatu kompetensi dasar yang terdiri dari aspek keterampilan berbahasa yaitu menyimak, berbicara, membaca dan menulis (Anggraini, 2016).

Sebagai fenomena sosial, bahasa merupakan wujud dari bentuk perilaku sosial yang digunakan sebagai alat komunikasi sedangkan budaya Budaya lahir dan dikembangkan oleh manusia, melalui akal dan pikiran, kebiasaan dan tradisi. (Muhyidin, n.d.). Adapun hubungan subordinatif lainnya lahir dari etika berbahasa yang mengatur bagaimana, kapan dan bagaimana bahasa digunakan sesuai dengan norma-norma sosial. Orang bima juga menjunjung tinggi etika berbahasa. Masyarakat Bima masih menjunjung tinggi nilai-nilai norma sosial. Di luar sana ada saja yang mengatakan bahwa orang Bima gaya berbicaranya sedikit lebih keras daripada orang jawa, namun nyatanya tidak semua wilayah di Bima menggunakan gaya bicara yang sama dan hal ini tidak bisa ditarik kesimpulan bahwa wataknya juga keras.

Seperti yang disampaikan oleh HN seorang mahasiswa yang merupakan anggota club motor di Bima "Kalau menurut pengalaman saya, ada teman dari luar daerah sewaktu datang ke Bima dan saat itu saya membawanya ke Uma lengge di Wawo. Teman tersebut mendengar kabar kalau orang wilayah timur itu keras, tapi waktu dia bertemu langsung dengan masyarakat di sini banyak yang ramah dan mengapa budaya sebagus Uma Lengge ini kurang disoroti pemerintah pusat dan banyak pantai-pantai di sini yang bagus." (Hasil wawancara pada tanggal 2 Juni 2021).

Asumsi dari teman $\mathrm{HN}$ tersebut sangat subjektif karena tidak semua fenomena yang ia ketahui bisa dikaitkan dengan budaya setempat. Hal tersebut kembali kepada pribadi masingmasing individu. Di setiap daerah pasti ada yang mendominasi dari gaya bicara. Walaupun Bahasa Bima tadi di beberapa daerah digunakan dengan gaya komunikasi yang lantang atau terihat keras bukan berarti itu hatinya keras. Tapi, memang kebiasaan daerah yang dekat pegunungan kalau berbicara dominan gaya komunikasi yang lugas supaya terdengar jelas. Sehingga kalau bahasa gaulnya sekarang "ngegas". Keseluruhannya tergantung dari kebiasaan yang terbentuk di lingkungannya. Hal ini sejalan dengan apa yang disampaikan oleh ND "Kalau saya melihatnya dominan gaya komunikasinya aja beda di wilayah saya yang dekat bukit-bukit mungkin dulu nenek moyang kami itu kalau bicara supaya kedengaran harus lantang. Kalaupun dikaitkan dengan etika berbahasa tergantung dengan siapa kami berbicara tidak mungkin kami berbicara dengan gaya komunikasi kami kepada yang bukan sesama masyarakat setempat. "(Hasil wawancara pada tanggal 2 Juni 2021).

Hal diatas menunjukkan bahwa etika berbahasa dalam gaya berkomunikasi menjadi bentuk toleransi. Peneliti juga mengamati langsung pada pembelajaran Public Speaking baik melalui tugas video maupun tatap muka cara bicara HN di kelas sangat menyesuaikan dengan siapa dia berbicara, tujuannya dan pemilihan katanya tepat. Berdasarkan data video yang telah diperoleh, banyak juga mahasiwa yang mengalami perubahan gaya bicara yang lebih formal dan tertata sesuai dengan tata cara berbicara di depan umum menggunakan bahasa yang lebih sesuai dengan EYD ( Ejaan Yang Disempurnakan). 
Mahasiswa sangat paham bahwa dengan mereka belajar budaya, maka mereka lebih memperhatikan etika berbahasa dan norma-norma sosial. Mereka juga dapat mengidentifikasi bagaimana cara berbicara di depan khalayak dengan orang-orang yang sebudaya, tetapi berbeda latar belakang pendidikan termasuk juga dengan orang-orang yang berbeda budaya. Perubahan kebudayaan akan selalu menegiringi perubahan dalam masyarakat yang menjadi wadah dari kebudayaan tersebut (Rosana, 2017).

\section{KESIMPULAN}

1. Peranan pengetahuan bahasa, budaya dan implikasinya terhadap public speaking mahasiswa Bima Program Studi Ilmu Komunikasi STISIP Mbojo Bima pada semester empat tahun akademik 2020-2021 yaitu antara lain :

a) Bagi mahasiswa Bima, bahasa dan budaya memegang peranan penting dalam menciptakan dan memelihara komunikasi khususnya di ruang public (public speaking). Mereka menggunakan bahasa Indonesia dalam konteks formal dimana khalayaknya berasal dari budaya yang berbeda. Namun, beberapa memilih untuk mencampur bahasa Indonesia (bahasa resmi) dan bahasa Mbojo (bahasa lokal) untuk khalayak dari budaya yang sama, orang tua dan orang yang kurang berpendidikan sebagai cara yang tepat untuk menghormati mereka.

b) Mahasiswa Bima memahami pola hubungan koordinatif dan subordinatif dengan baik. Mereka menyadari bahwa ada aspek-aspek linguistik yang mempengaruhi gaya mereka berbahasa. Namun, mereka masih terus belajar. Sebagai mahasiwa komunikasi, mereka juga belajar etika berbahasa karena bahasa dan budaya berada dalam satu bingkai karena keduanya tidak dapat dipisahkan ataupun dipecahkan. Ilmu pengetahuan bahasa dapat diidentifikasi dalam perspektif Ilmu Komunikasi. Sama halnya dengan budaya, komunikasi memandang budaya sebagai bagian yang sangat berperan besar dalam berinteraksi.

\section{SARAN}

Pengembangan ide selanjutnya untuk kajian etnografi harus lebih menyentuh sisi kearifan lokal dari masyarakat setempat. Peneliti bisa memilih sasaran wilayah yang masyarakatnya masih kental dengan budaya tertentu dan kontribusi untuk pendidikannya dapat dijelaskan.

\section{DAFTAR PUSTAKA}

Achmad, Z. A., \& Ida, R. (2018). Etnografi Virtual Sebagai Teknik Pengumpulan Data Dan Metode Penelitian. The Journal of Society \& Media, 2(2), 130. https://doi.org/10.26740/jsm.v2n2.p130-145

Anggraini, S. (2016). Budaya literasi dalam komunikasi. Wacana, XV(3), 264-279.

Camalia, M. (2015). Toponimi Kabupaten Lamongan (Kajian Antropologi Linguistik). PAROLE: Journal of Linguistics and Education, 5(1), 74. https://doi.org/10.14710/parole.v5i1.8625

Damayanti, I., \& Purnamasari, S. H. (2019). Hambatan komunikasi dan stres orangtua siswa tunarungu sekolah dasar. Jurnal Psikologi Insight, 3(1), 1-9.

Deliani, S. (2012). Toponimi Kota Medan (dalam Relativitas Linguistik). Linguistic.Fib.Ui.Ac.Id, 266-270.

Fitrananda, C. A., Anisyahrini, R., Iqbal, M., Studi, P., Komunikasi, I., \& Pasundan, U. (2018). Pelatihan Public Speaking untuk Menunjang Kemampuan Presentasi Bagi Siswa SMAN 1 Margahayu Kabupaten Bandung. Jurnal Pengabdian Kepada Masyarakat MADANI, 4(2), 66-69.

Iswatiningsih, D. (1994). Etnografi Komunikasi : Sebuah Pendekatan Dalam Mengkaji. Seminar Nasional Prasasti (Pragmatik: Sastra Dan Linguistik) Marah, 38-45.

Lauder, M. R. (2002). Reevaluasi Konsep Pemilah Bahasa Dan Dialek Untuk Bahasa Nusantara. Makara Human Behavior Studies in Asia, 6(1), 37. 
https://doi.org/10.7454/mssh.v6i1.31

Marlina, Y. I. (2019). Bentuk kesalahan berbahasa ruang publik: kajian struktural bahasa [Universitas Muhamadiyah Surakarta]. http://eprints.ums.ac.id/76214/

Muhyidin, A. (n.d.). Pemertahanan Nilai-Nilai Budaya Lokal dalam Pemelajaran Sastra di Sekolah | Badan Pengembangan dan Pembinaan Bahasa, Kementerian Pendidikan dan Kebudayaan. Retrieved June 19, 2021, from http://badanbahasa.kemdikbud.go.id/lamanbahasa/node/306

Mujib, A. (2009). Hubungan Bahasa dan Kebudayaan (Perspektif Sosiolinguistik). Adabiyyāt: Jurnal Bahasa Dan Sastra, 8(1), 141. https://doi.org/10.14421/ajbs.2009.08107

Pratama, R. (2019). Aspek Kebudayaan Material dan Non Material pada Gerai Kopi Starbucks. Endogami: Jurnal Ilmiah Kajian Antropologi, 3(1), 100. https://doi.org/10.14710/endogami.3.1.100-106

Rosana, E. (2017). Ellya Rosana, Dinamisasi Kebudayaan..... Al-AdYaN, XII(1), 16-30.

Simatupang, O., \& Lubis, L. A. (2015). Gaya berkomunikasi dan adaptasi budaya mahasiswa batak di yogyakarta. Jurnal Komunikasi ASPIKOM, 2(5), 314-329.

Swestin, G. (2011). Retorika Modern. 1-83. http://repository.bakrie.ac.id/1227/1/panduan mendeley.pdf

Wijaya, H. (2018). Analisis Data Kualitatif Model Spradley. Research Gate. https://www.researchgate.net/publication/323557072

Windiani, \& Nurul, F. (2016). Menggunakan metode etnografi dalam penelitian sosial. Dimensi Jurnal Sosiologi, 9(2), 87-92.

Wt, N. (2014). Implikatur ungkapan kalembo ade dalam bahasa bima [Universitas Mataram]. http://eprints.unram.ac.id/9560/1/NELY HUSNIA WT.pdf

Wulandari, T. A. (2017). PUBLIC SPEAKING Public Speaking .. Penting? 